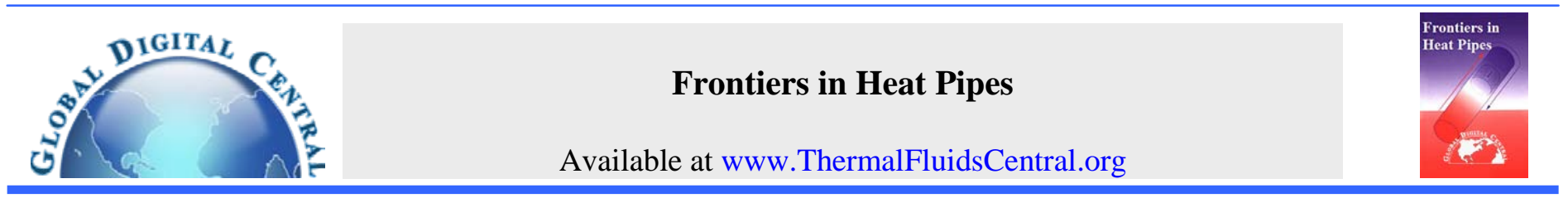

\title{
DEVELOPMENT OF TUBULAR Ni WICK USED IN LHP FOR SPACE APPLICATIONS
}

\author{
S. K. Samanta*, Bharat B. Sharma, Prosenjit Das, A. K. Lohar \\ Foundry Group, CSIR-Central Mechanical Engineering Research Institute, Durgapur, India.
}

\begin{abstract}
Present research is focused on porous tubular wick development, which is considered as the heart of the Loop heat pipes (LHP) specifically used for space applications, such as satellites and space craft's. Basic purpose of a wick is to generate capillary pumping pressure required to transport a working fluid along a two-phase heat transfer loop. Wicking structures are generally made of wire meshes or sintered metal powders. Present work establishes Metal Injection Moulding (MIM) as a potential route for the manufacturing of tubular wicks in the near-net shape form, discarding any need of further machining for creating vapour removal channels/grooves on the outer surface. Nickel powder along with polypropylene (PP) powder and thermoplastic binder consisting of paraffin wax (PW) and low density polyethylene (LDPE) are used to produce feedstock for injection moulding. Green compact of tubular wicks prepared by injection moulding is then debound and sintered to get the final porous structure. Further characterization of the tubular wicks sintered at $900^{\circ} \mathrm{C}$ for 60 minutes reveals porosity level of $55 \mathrm{vol} \%$, avg. capillary pore diameter of $2.6 \mu \mathrm{m}$, permeability of $1.94 \times 10^{-12} \mathrm{~m}^{2}$ and thermal conductivity of $9.37 \mathrm{~W} / \mathrm{mK}$. SEM observation of wick samples shows well connected micro porous network responsible for generation of capillary pumping pressure.
\end{abstract}

Keywords: Ni powder, Tubular Wick, LHP, MIM.

\section{INTRODUCTION}

Loop heat pipes are two phase heat transfer devices used in thermal management of electronic system by transferring large amount of heat load with capillary pumping of a working fluid around the loop. Figure 1 shows the schematic diagram of a LHP. The capillary pumping pressure is generated by the porous wick located inside the evaporator of the loop heat pipe through its fine pore structure (Maydanik,2005; Li and Cheng, 2010).

Presently Nickel, titanium, copper and stainless steel (Reimbrechta et al., 1999; Patukhov et al., 2003; Reay and Kew, 2006; Joung et al., 2008 and Gongming et al., 2009) are the most widely used metal powders for capillary wicks. Earlier work towards development of wick for Loop heat pipe applications presents few methods. Detailed investigations on the fabrication process are still needed to find the most convenient and economic way of producing wicks having expected properties. Tap powder sintering technique using a graphite matrix is used by Reimbrechta et al.(1999) to prepare Ni wicks dedicated for capillary pump applications. Graphite is recommended because it shows a low interaction with nickel at the usual sintering temperatures. Gongming et al. (2009) used two different methods, the cold-pressing sintering and direct loose sintering for development of $\mathrm{Ni}$ and $\mathrm{Ni}-\mathrm{Cu}(90 \%$ nickel and $10 \%$ copper) wicks for loop heat pipes. The optimal $\mathrm{Ni}-\mathrm{Cu}$ capillary wick is prepared using direct loose sintering technique, with mean pore radii of $0.54 \mu \mathrm{m}$. Huang and Franchi (2008) fabricated bimodal wick structure using copper screen mesh and two powder materials (nickel filamentary powder and spherical copper powder). But these wicks may be produced with inherent shortcomings.
When the wicks are long and cylindrical, powder packing density does not become same throughout the length. In the case of cold pressing sintering, density gradient occurs due to loss of pressure transmission from end portions to the central zone along the length. The density gradient causes uneven sintering. As a result, maintaining porosity, pore size distribution and dimensional tolerances throughout the wick becomes difficult. Besides that the vapour removal grooves are cut by machining on the periphery of the wick along the length and the pores on the grove surface may get blocked during machining which degrades efficiency of the loop heat pipe.

In view of the above shortcomings, the present research reports a novel approach for manufacturing of wicks for LHPs in space application using the modified metal injection moulding (MIM) route. The wicks are manufactured with in-built vapour removal channels, discarding the need of further machining. Nickel powder is considered in this work for development of porous wicks.

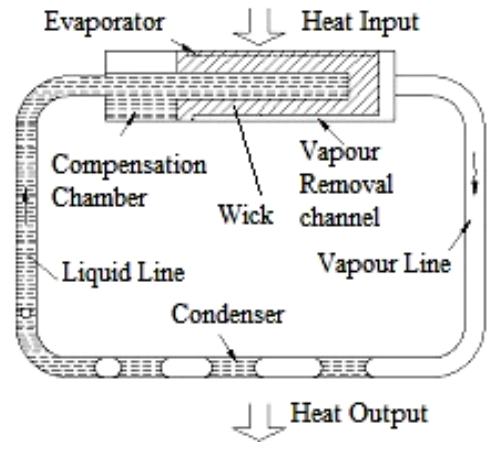

Fig. 1 Schematic diagram of the Loop Heat Pipe.

\footnotetext{
* Corresponding author. Email: sudip@cmeri.res.in
} 


\section{EXPERIMENTAL PROCEDURE}

Prototype Ni wick has been manufactured in this work in near-net shape form with in-built vapour removal channels following Metal Injection Moulding (MIM) route. Dimensions of the wicks were set to $15 \mathrm{~mm}$ and $10 \mathrm{~mm}$ for the outer and inner diameter respectively, with total length of $45 \mathrm{~mm}$ for prototype one and $275 \mathrm{~mm}$ for actual one respectively.

The nickel powder with average particle size of around $12 \mu \mathrm{m}$ used in the present work has been procured from Sandvik Osprey Limited, United Kingdom. Nickel powder along with polypropylene (PP) powder (average particle size of around $35 \mu \mathrm{m}$ ) and thermoplastic binder consisting of paraffin wax (PW) and low density polyethylene (LDPE) are mixed at $140^{\circ} \mathrm{C}$ in a sigma blade mixer to produce feedstock for injection moulding. Polypropylene powder is used to increase porosity in the wick and it does not melt like binder rather it behaves like nickel powder in the feedstock. The composition of the feedstock is shown in Table 1. The prepared feedstock is pelletized and injected into the mould and shape of the component is formed. Injection moulding has been carried out at $140^{\circ} \mathrm{C}$ using DGP Windsor make 150 Ton injection moulding machine and mould temperature is kept constant at $40^{\circ} \mathrm{C}$ by circulating water through the cooling channel inside the mould. At this stage, the component is called Green Compact. After the completion of injection stage, the role of binder is over. Debinding of the green compact is carried out in two steps: solvent debinding at $45^{\circ} \mathrm{C}$ in n-hexane and ethanol mixture (to remove PW) followed by thermal debinding at $500^{\circ} \mathrm{C}$ (to remove LDPE, PP powder and rest of the $\mathrm{PW}$ ) in pure hydrogen atmosphere. During debinding, binder as well as polypropylene are removed creating huge pores in the debound compact. The debound compact is then sintered at $900^{\circ} \mathrm{C}, 930^{\circ} \mathrm{C}$ and $950^{\circ} \mathrm{C}$ for 30,60 and 90 minutes respectively in pure hydrogen atmosphere using Naskar \& Co. make tube furnace and thereby sintered nickel wicks have been developed with inbuilt axial vapor removal groves on the outer surface. Experimental facilities used for development of prototype tubular wick are shown in Fig. 2. Due to application of heat, strong particle to particle bonding occurs at the contact points among the particles by neck formation similar to that in conventional powder metallurgy. The optimum sintering condition is identified as $900^{\circ} \mathrm{C}$ and 60 minutes which produces 55\% volume porosity and 2.6 micron average pore diameter in the sintered Ni wick. Microscopic observations are carried out using optical microscopy and SEM (Scanning electron microscopy) reveals interconnected porosity and also supports experimental findings of average pore diameter.
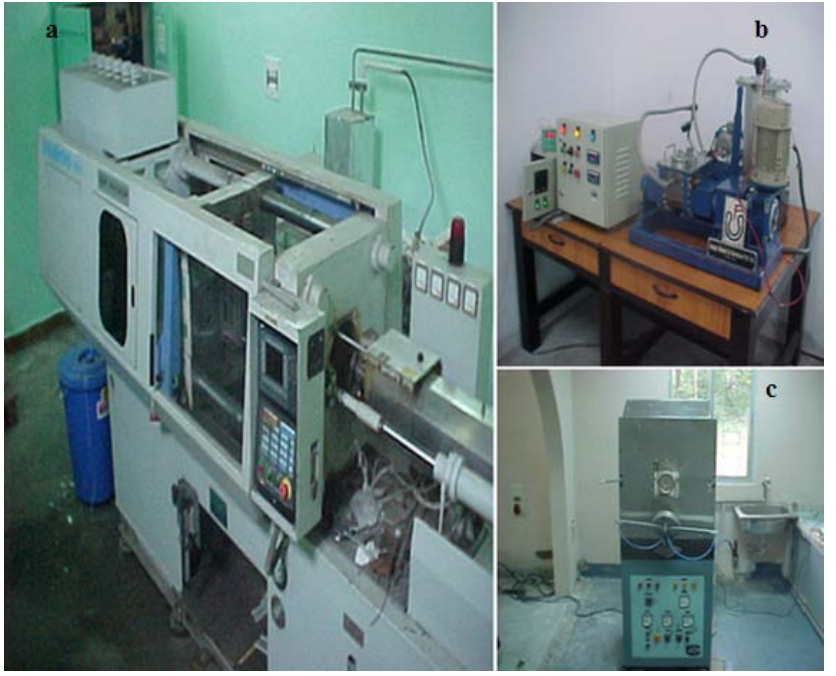

Fig. 2 (a) Injection Moulding machine, (b) Sigma blade mixer and (c) sintering and thermal debinding furnace.
TABLE 1: Composition of the Feedstock prepared for Metal Injection moulding.

\begin{tabular}{|c|c|c|c|}
\hline \multirow{2}{*}{$\begin{array}{c}\text { Ni Powder } \\
(\text { wt.\%) }\end{array}$} & $\begin{array}{c}\text { Polypropylene Powder } \\
\text { (wt.\%) }\end{array}$ & \multicolumn{2}{|c|}{$\begin{array}{c}\text { Binder } \\
(\text { wt.\%) }\end{array}$} \\
\cline { 3 - 4 } & & Parrafin wax & $\begin{array}{l}\text { Low Density } \\
\text { Polyethylene }\end{array}$ \\
\hline 87.5 & 5.5 & 5 & 2 \\
\hline
\end{tabular}

\subsection{Determination of Capillary properties}

Property of the sintered wicks are characterized in terms of effective porosity and pore diameter. The porosity of the wicks is geometrically determined measuring their mass (m), length (L), external diameter $\left(\phi_{\mathrm{c}}\right)$ and internal diameter $\left(\phi_{\mathrm{i}}\right)$. For the measurements, an electronic weight measuring machine (make: Afcoset electronic balance, Model: FX-400, Resolution: $0.001 \mathrm{gm}$ ) and a micrometer (make: Mitutoyo, Japan, resolution: $0.001 \mathrm{~mm}$ ) are used. The volumetric fraction of pores is then calculated according to:

$$
\varepsilon=100\left(1-\rho / \rho_{\mathrm{Ni}}\right)
$$

Where, $\varepsilon$ is the volumetric fraction of pores of the wick (\%), $\rho$ is the apparent specific mass $(\mathrm{g} / \mathrm{cm} 3)$ and $\rho_{\mathrm{Ni}}$ is the specific mass of nickel $\left(\rho_{\mathrm{Ni}}=8.9 \mathrm{~g} / \mathrm{cm} 3\right)$.

As capillary pumping pressure depends on pore size distribution. It is very important parameter to be considered in wick manufacturing. Extrusion Flow Porometry also known as Capillary Flow Porometry (Model: CFP-1100-AEX) is used to measure the pore size in the developed Ni wick.

\section{RESULTS AND DISCUSSIONS}

Figure 3 shows the prototype (45 mm long) and actual tubular ( $275 \mathrm{~mm}$ long) Ni wick developed in this work. The wick are sintered at optimum sintering condition of $900^{\circ} \mathrm{C}$ and 60 minutes, as identified in the current work. It may be mentioned here that the actual wick is developed incorporating the shrinkage (during injection moulding and sintering stage) calculated on prototype wick.

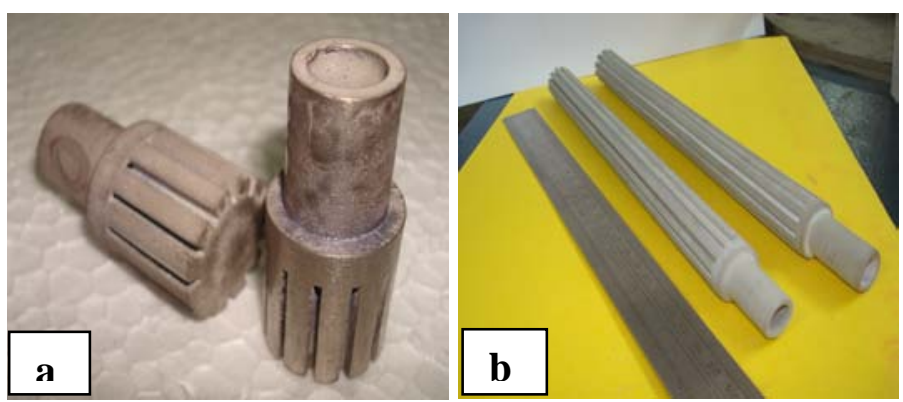

Fig. 3 Photograph of sintered Ni wick a) prototype (45mm long) and b) actual (275 mm long).

\subsection{DSC study of the Feedstock Material}

Differential Scanning Calorimetric (DSC) analysis of the feedstock is very important to find out appropriate injection temperature for injection moulding. Figure 4 shows the DSC curve of the feedstock during heating. Three endothermic peaks are observed at $60^{\circ} \mathrm{C}, 92^{\circ} \mathrm{C}$ and $155^{\circ} \mathrm{C}$ corresponding to the binder constituents and polypropylene powder. The first peak at $60^{\circ} \mathrm{C}$ signifies melting of Paraffin Wax and the second peak at $109^{\circ} \mathrm{C}$ corresponds to the melting of LDPE. Whereas the third peak at $155^{\circ} \mathrm{C}$ corresponds to the melting PP powder. In order to create porosity during the debinding and subsequently in the sintering stage, polypropylene should be in powder 
form during injection moulding. So the injection temperature of the feedstock should be below $155^{\circ} \mathrm{C}$ and as the binder fully melts at $92^{\circ}$ $\mathrm{C}$, the minimum injection temperature of the feedstock should be above $92^{\circ} \mathrm{C}$. In the present investigation, the feedstock has been injected at $140^{\circ} \mathrm{C}$.

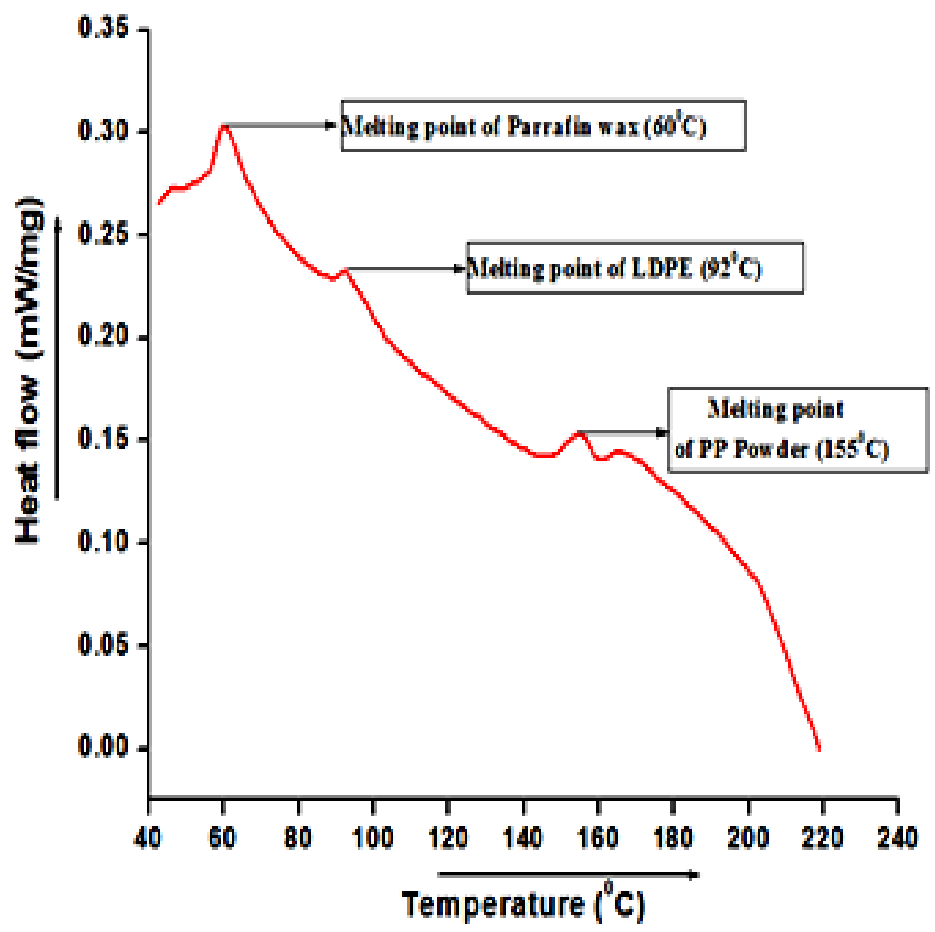

Fig. 4 DSC curve of the Feedstock.

\subsection{Porosity, Pore diameter, Permeability and Thermal conductivity}

Among the different sintering conditions (sets of sintering temperature and soaking time), the appropriate condition is identified as $900^{\circ} \mathrm{C}$ and 60 minutes. It results in obtaining $2.6 \mu \mathrm{m}$ average capillary pore diameter, around $55 \%$ volume porosity, $1.94 \times 10^{-12} \mathrm{~m}^{2}$ permeability and thermal conductivity of $9.37 \mathrm{~W} / \mathrm{mK}$ without further densification. Figure 5 shows the \% porosity, average pore diameter, and permeability of the sintered $\mathrm{Ni}$ wick under different temperature and time combinations. It may be mentioned here that the permeability is calculated following the Kozeny-Carmen equation:

$$
k=\frac{d^{2} \varepsilon^{2}}{180(1-\varepsilon)^{2}}
$$

where, $k$ is permeability and $d$ is pore diameter.

It is observed from Fig. 5(a) that \% porosity decreases with increasing temperature for all sintering times which is in agreement with usual cases reported in the literature (Tracey, 1981; Whittemore and Sipe, 1974). But, strong dependence of \% porosity has been observed on sintering temperature. Initial pore growth observed for all sintering times may be due to surface diffusion and particle size distribution effects mechanisms (Falamaki et al., 2004). For same sintering times with increasing sintering temperatures, sintering densification predominates over pore growth and pore size get decreased. Further increase in average pore size observed at higher temperatures due to pore coarsening mechanisms such as Ostwald ripening, grain coarsening (Schmelzer et al., 1995).
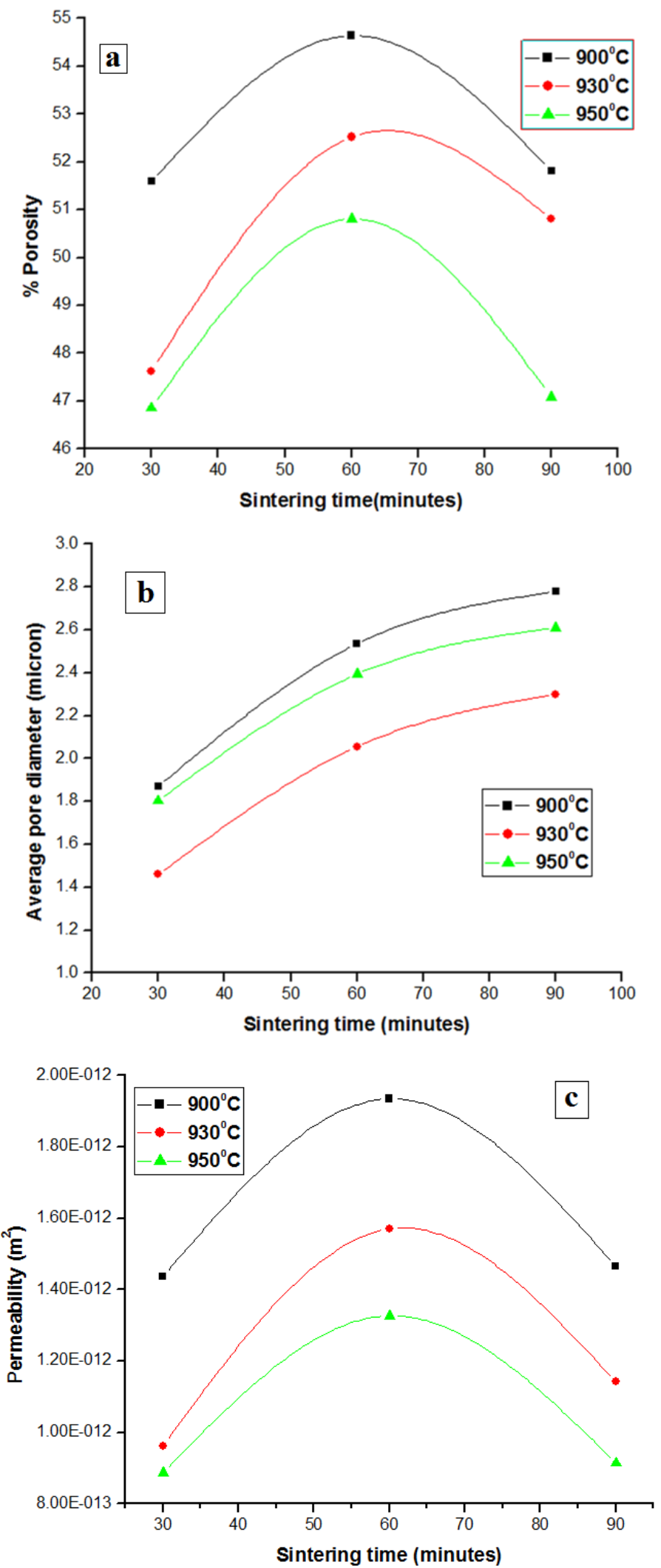

Fig. 5 Variation of (a) \% Porosity, (b) Average pore diameter and (c) permeability with different sintering temperature and time.

Figure 5(c) shows the variation of calculated permeability at different sintering condition. As the porosity increases, permeability increases and vice versa. Generation of capillary pumping pressure depends on pore size distribution, since smaller the pore size, higher the capillary pumping pressure. Wick samples sintered according to ideal 
condition, as stated earlier and different pore sizes measured in the sample by Extrusion flow porosimetry technique are shown in Fig. 6(a). Cumulative pore size distribution curve, shown in Fig. 6(b) reveals that at least $90 \%$ of the pores have less than $3.5 \mu \mathrm{m}$ diameter what indicates the quality of the wick.
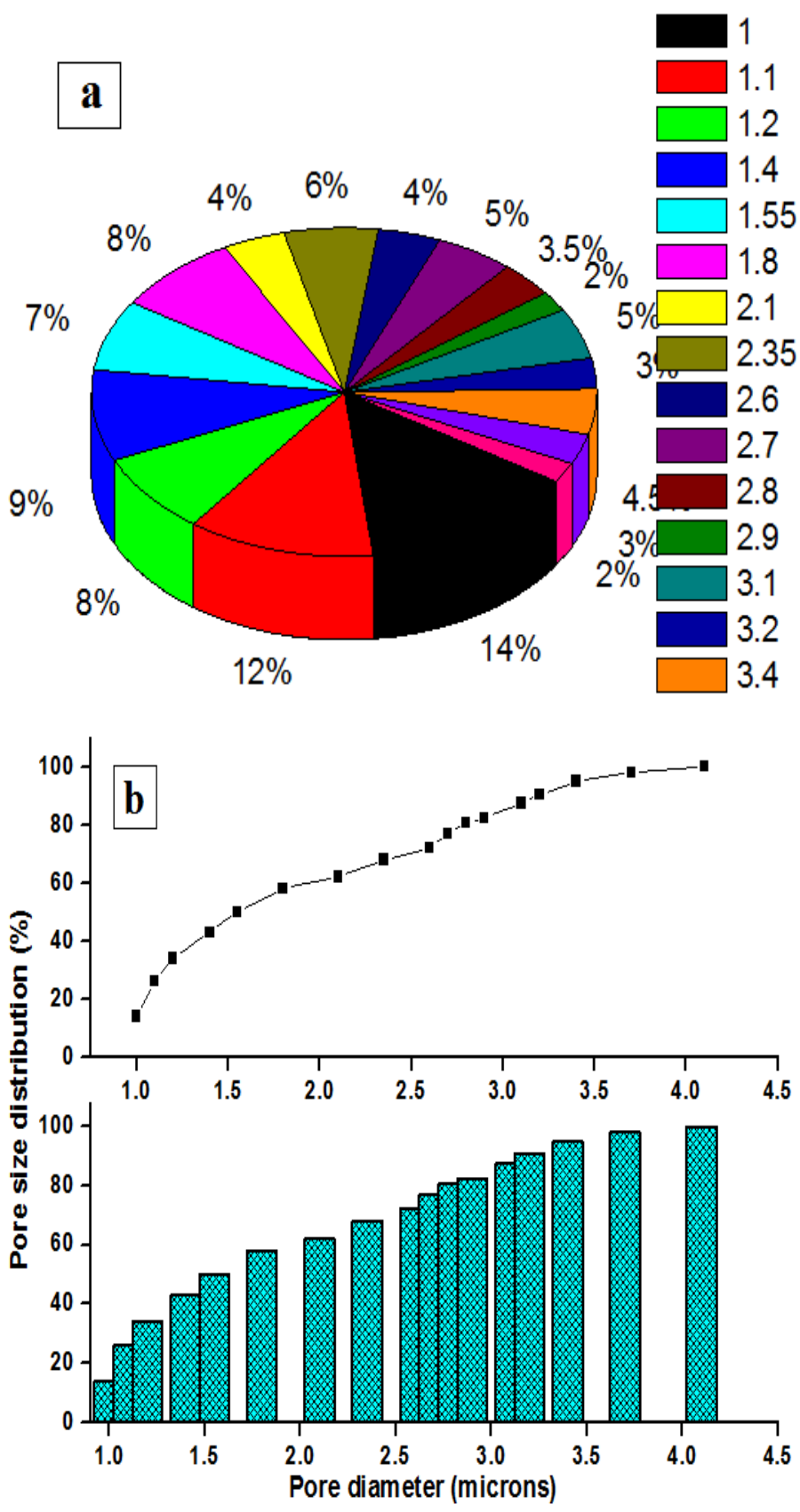

Fig. 6 (a) Standard and (b) Cumulative pore size distribution in the sintered Ni wick samples.

The majority of heat load is used in vaporization on the outer surface of wick (Launay et al., 2007). The rest of heat input (called "heat leak") is conducted across the wick and is proportional to the effective thermal conductivity (ETC) of the capillary wicks (Gongming et al., 2010). Lower thermal conductivity of the porous wick ensures lesser heat conduction to the liquid inside the wick inner surface and maintains the operating temperature and thus the thermal resistance of the whole LHP. Variation of the measured effective thermal conductivity at different sintering condition has been shown in Fig. 7.

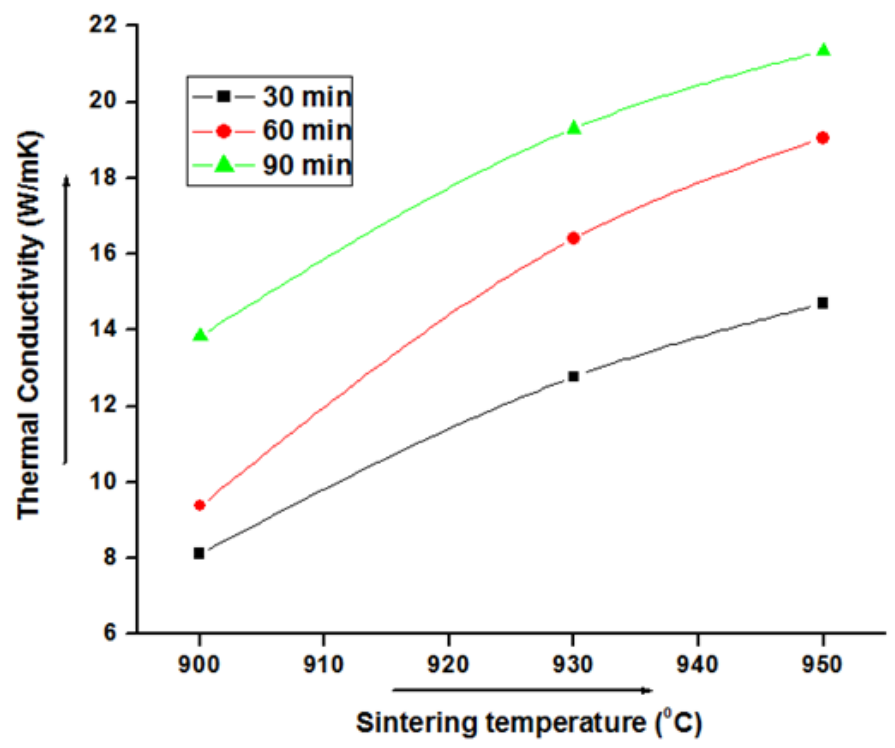

Fig. 7 Variation of effective thermal conductivity with different sintering conditions

As the sintering temperature increases coalescence of Nickel particle takes place which leads to densification (figure $5 a$ ), and hence the effective thermal conductivity increases. At optimum sintering condition ( $900{ }^{\circ} \mathrm{C}, 60 \mathrm{~min}$.), $9.37 \mathrm{~W} / \mathrm{mK}$ of ETC has been achieved which is as per with the reported literature (Reay and Kew, 2006).

\subsection{SEM investigation of tubular wick}

Optical and SEM image of porous tubular wick are shown in Figs. 8 and 9 respectively. Most of the paraffin wax component of the binder gets removed by solvent debinding process and rest of the paraffin wax, LDPE and Polypropylene powder during thermal debinding. Sintered specimen shows large pores along with some finer ones. Large pores originated from (i) large Polypropylene particles, get removed from matrix in thermal debinding stage and also (ii) from voids caused by the incomplete deformation and adhesion of powder particles in collapsed dimples at the centers and boundaries of granules in the green compacts. Large pores are visible in optical micrograph but to reveal finer interconnected porosity, SEM characterization is done using samples taken along the cross-section of the sintered specimens and are shown in Fig. 9 for optimum sintering condition. SEM images reveal the larger pores, created due to removal of Polypropylene particles as stated earlier, are surrounded by higher amount of uniform interconnected finer pores (around $2.4 \mu \mathrm{m}$ size). This interconnected pore network is responsible for generation of capillary pressure in the wick.

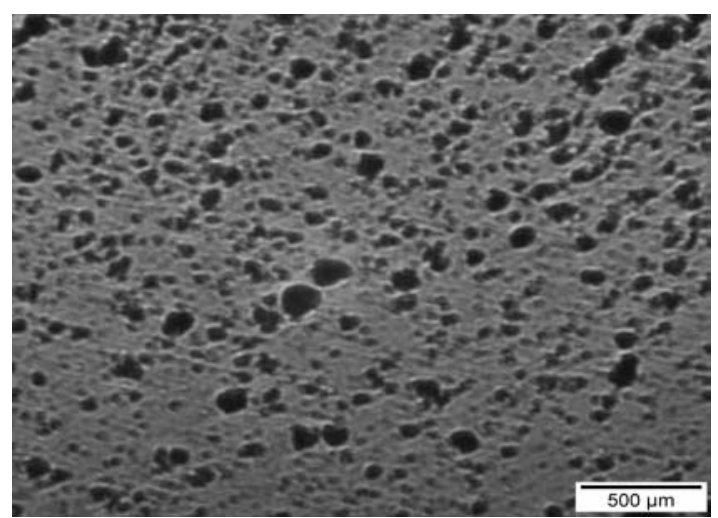

Fig. 8 Optical micrograph of the porous tubular Ni wick at $900^{\circ} \mathrm{C}$ and 60 minutes. 

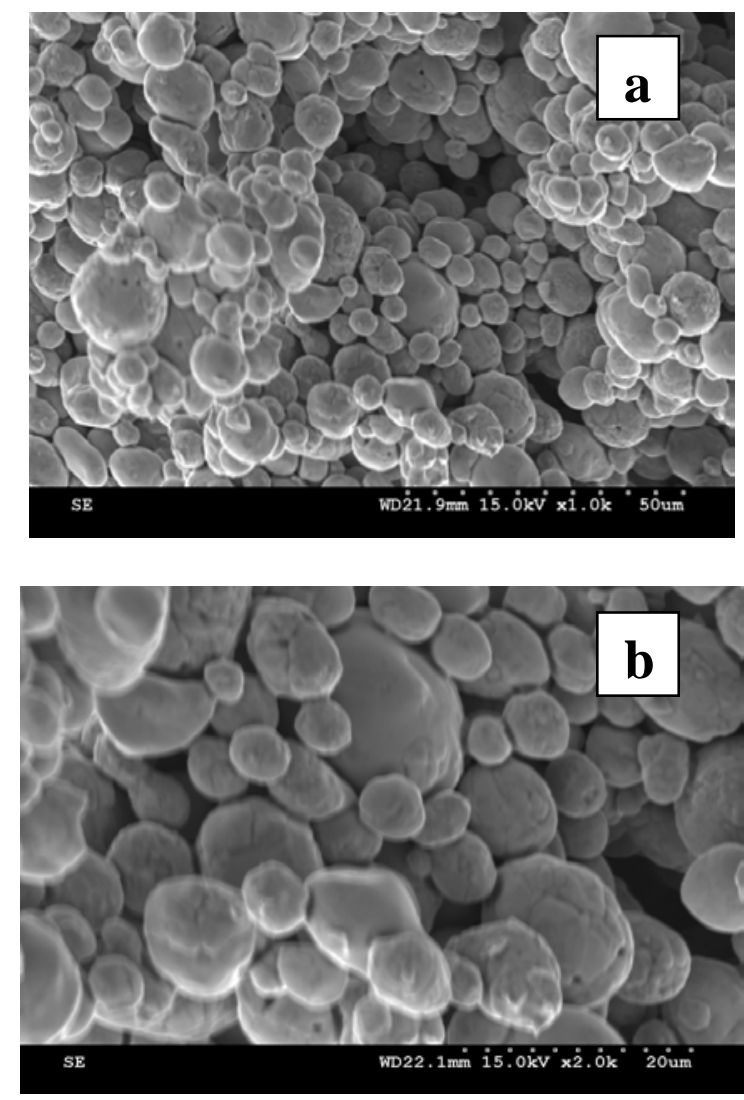

Fig. 9 SEM micrograph of the wick along cross-section for optimum sintering condition $\left(900^{\circ} \mathrm{C}\right.$ and $60 \mathrm{~min}$.) at a) magnification $1000 \mathrm{X}$ and b) magnification 2000X.

\section{CONCLUSIONS}

Tubular Ni wick with in-built vapour removal grooves has been manufactured following a new approach that is Metal Injection Moulding route with satisfactory capillary properties required for LHP's such as porosity, pore diameter and effective thermal conductivity. Ni powder has been used for generation of fine interconnected pores. PP powder enhances overall porosity and permeability and establishes interconnected pore network by diametrically connecting the nickel powders adhered on its periphery. Out of three different set of sintering temperatures and times such as $900^{\circ} \mathrm{C}, 930^{\circ} \mathrm{C}, 950^{\circ} \mathrm{C}$ and $30,60,90$ minutes respectively, ideal sintering condition is identified as $900^{\circ} \mathrm{C}$ and 60 minutes. That results in obtaining around 55\% porosity, $2.6 \mu \mathrm{m}$ (avg.) capillary pore diameter, $1.94 \times 10^{-12} \mathrm{~m}^{2}$ permeability and 9.37 $\mathrm{W} / \mathrm{mK}$ effective thermal conductivity. Experimental findings reveal that $90 \%$ of the pores are having diameter less than $3.5 \mu \mathrm{m}$. SEM investigation of porous wicks reveals that finer pores are of around 2.4 $\mu \mathrm{m}$ size and is in good agreement with experimental findings of 2.6 $\mu \mathrm{m}$. Therefore it can be concluded that, the present research establishes a novel route that is MIM for fabrication of porous tubular Ni wicks.

\section{ACKNOWLEDGEMENTS}

Authors would like to thank Prof. (Dr.) Gautam Biswas, Director, CSIR-Central Mechanical Engineering Research Institute, Durgapur, Dr. Amrit Ambiaranjan, ISRO Satellite Centre, Bangalore and Dr. Kripal Singh, CSIR-CSMCRI for their support and encouragement to carry out this research work. Authors would like to thank members of the Foundry Group for their efforts to complete this work successfully.

\section{REFERENCES}

Falamaki, C., Afarani, M. S. and Aghaie, A., 2004 "Initial sintering stage pore growth mechanism applied to the manufacture of ceramic membrane supports", Journal of the European Ceramic Society, 24, 2285-2292.

http://dx.doi.org/10.1016/S0955-2219(03)00643-5

Gongming, X., Kehang, C., Yong, Z. and Lin, C., 2009 "Development of sintered Ni-Cu wicks for loop heat pipes", Science in China Series E: Technological Sciences, 52(6),1607-1612.

http://dx.doi.org/10.1007/s11431-009-0180-7

Gongming, X., Kehang, C., Yong, Z. and Lin, C.,2010, "Reduction of effective thermal conductivity for sintered LHP wicks", International $J$. ,of Heat and Mass Transfer,53,2932-2934.

http://dx.doi.org/10.1016/j.ijheatmasstransfer.2010.02.056

Huang, X. and Franchi, G., 2008, "Design and fabrication of hybrid bimodal wick structure for heat pipe application", J Porous Mater, (15), 635-64.

http://dx.doi.org/10.1007/s10934-007-9143-1

Joung W., Yu T. and Lee J.,2008, "Experimental study on the loop heat pipe with a planar bifacial wick structure", Int. J. Heat Mass Transfer 51(7-8), 1573-1581. http://dx.doi.org/10.1016/j.ijheatmasstransfer.2007.07.048

Launay S., Sartre V. and Bonjour J.,2007, "Parametric analysis of Loop Heat Pipe Operation: A Literature Review", Int. J. Thermal Sciences, 46, 621-636.

http://dx.doi.org/10.1016/j.ijthermalsci.2006.11.007

Li J., Zou Y. and Cheng L., 2010, "Experimental study on capillary pumping performance of porous wick for loop heat pipe", Experimental Thermal and Fluid Science, 34, 1403-1408.

http://dx.doi.org/10.1016/j.expthermflusci.2010.06.016

Maydanik, Y. F., 2005,"Loop heat pipes", Appl. Therm Engg, 25(5-6), 635-657.

http://dx.doi.org/10.1016/j.applthermaleng.2004.07.010

Patukhov V., Maidanik Y. F. and Vershinin C.,2003, "Miniature loop heat pipes for electronic cooling", Appl. Therm Engg. 23(9), 1125-1135.

http://dx.doi.org/10.1016/S1359-4311(03)00046-2

Reay D. and Kew P., 2006, Heat Pipes, $5^{\text {th }}$ ed., ButterworthHeinemann, MA, USA.

Schmelzer, J., Moller, J. and Slezov, V.V., 1995 "Ostwald ripening in porous materials: The case of arbitrary Pore size distributions", Journal of Physics and Chemistry of solids, 56(8), 1013-1022.

http://dx.doi.org/10.1016/0022-3697(95)00021-6

Tracey, V.A.,1981,"Sintering of Porous Nickel - Theoretical and Practical Considerations", Modern Developments in Powder Metallurgy, (12), 423-438.

Whittemore, O.J. and Sipe, J.J., 1974, "Pore Growth during the Initial Stages of Sintering Ceramics", Powder Technology, 9(4),159-164. http://dx.doi.org/10.1016/0032-5910(74)80027-6 